BMC

Evolutionary Biology

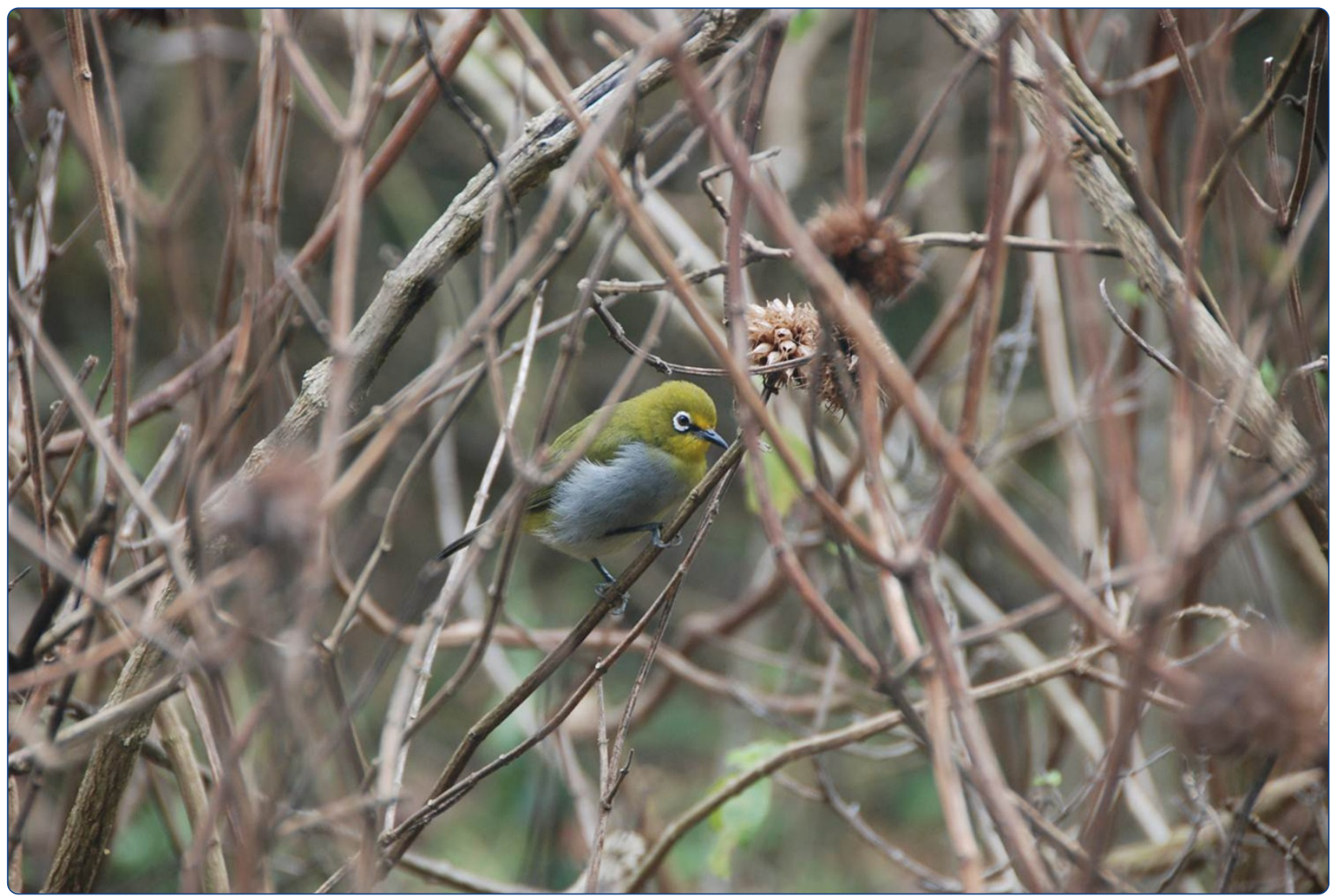

The evolution of contact calls in isolated and overlapping populations of two white-eye congeners in East Africa (Aves, Zosterops)

Husemann et al. 


\title{
The evolution of contact calls in isolated and overlapping populations of two white-eye congeners in East Africa (Aves, Zosterops)
}

\author{
Martin Husemann ${ }^{1,2}$, Werner Ulrich ${ }^{3}$ and Jan Christian Habel ${ }^{1 *}$
}

\begin{abstract}
Background: Closely related species often occur in geographic isolation, yet sometimes form contact zones with the potential to hybridize. Pre-zygotic barriers may prevent cross breeding in such contact zones. In East Africa, White-eye birds have evolved into various species, inhabiting different habitat types. Zosterops poliogaster is found in cool and moist cloud forests at higher elevations, whereas Z. abyssinicus is distributed across the dry and hot lowland savannahs. In most areas, these two species occur allopatrically, but in the contact zone where the mountain meets the savannah, the distributions of these species sometimes overlap (parapatry), and in a few areas the two taxa occur sympatrically. Acoustic communication is thought to be an important species recognition mechanism in birds and an effective prezygotic barrier for hybridisation. We recorded contact calls of both the lowland and highland species in (i) distinct populations (allopatry), (ii) along contact zones (parapatry), and (iii) in overlapping populations (sympatry) to test for species and population differentiation.

Results: We found significant differences in call characteristics between the highland and lowland species, in addition to call differentiation within species. The highland Z. poliogaster shows a strong call differentiation among local populations, accompanied by comparatively low variability in their contact calls within populations (i.e. a small acoustic space). In contrast, calls of the lowland Z. abyssinicus are not differentiated among local sites but show relatively high variability in calls within single populations. Call patterns in both species show geographic clines in relation to latitude and longitude. Calls from parapatric populations from both species showed greater similarity to the other taxon in comparison to heterospecific populations found in allopatry. However, where the two species occur sympatrically, contact calls of both species are more distinct from each other than in either allopatric or parapatric populations.

Conclusion: The contrasting patterns reflect divergent spatial distributions: the highland Z. poliogaster populations are highly disjunct, while Z. abyssinicus lowland populations are interconnected. Higher similarity in contact calls of heterospecific populations might be due to intermixing. In contrast, sympatric populations show reproductive character displacement which leads to strongly divergent call patterns.
\end{abstract}

Keywords: Allopatry, Bioacoustics, Contact calls, Parapatry, Reproductive character displacement, Sympatry, Zosterops abyssinicus, Zosterops poliogaster

\footnotetext{
* Correspondence: Janchristianhabel@gmx.de

${ }^{1}$ Terrestrial Ecology Research Group, Department of Ecology and Ecosystem Management, Technische Universität München, Hans-Carl-von-Carlowitz-Platz 2, D-85354 Freising-Weihenstephan, Germany

Full list of author information is available at the end of the article
}

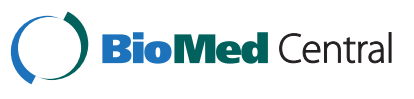

(c) 2014 Husemann et al.; licensee BioMed Central Ltd. This is an Open Access article distributed under the terms of the Creative Commons Attribution License (http://creativecommons.org/licenses/by/2.0), which permits unrestricted use, distribution, and reproduction in any medium, provided the original work is properly credited. The Creative Commons Public Domain Dedication waiver (http://creativecommons.org/publicdomain/zero/1.0/) applies to the data made available in this article, unless otherwise stated. 


\section{Background}

Speciation and the maintenance of species boundaries are a major focus in evolutionary biology. The evolution of new species is continuously counteracted by the intermixing of individuals from adjoining populations [1]. Reproductive barriers can prevent the admixture of incipient species and are of major importance in closely related species that occur in close geographic proximity [2-4]. When species occur in sympatry, prezygotic mechanisms leading to the correct mate choice often evolve before any post-zygotic mechanisms (e.g. hybrid sterility) can be established [5-8]. Differences in signalling characters often initially evolve as a byproduct of divergent ecological selection in allopatry $[9,10]$. When incipient species experience secondary contact, prezygotic isolation mechanisms can become enhanced as a result of selection against hybridization, a process termed reproductive character displacement [11-13]. This phenomenon has been documented for a variety of signalling characters, most commonly for acoustic communication. Examples come from a variety of organisms including grasshoppers, [14,15], crickets [16], amphibians [17,18], and birds [19-21].

The genus Zosterops is among the most species-rich bird genera worldwide and known for its high rates of microendemism and rapid speciation [22-25]. Geography and geological history have been identified as the main drivers of speciation in the genus [23]. Apart from differentiation driven by geographic isolation, intrinsic factors contribute to the species richness and often lead to a high level of endemism. For example, while many species of the genus are good dispersers [22], other species, especially narrow endemics, are characterized by 'behavioural flightlessness', the behavioural reluctance to disperse longer distances despite being able to fly, leading to differentiation $[26,23,27]$. In addition, representatives of the genus Zosterops seem to be morphologically and behaviourally dynamic. Rapid phenotypic change has been documented in Zosterops species and has been suggested to be an important feature of its greater potential for speciation $[23,28]$. If such rapid changes occur in reproductive characters, reproductive isolation can evolve quickly leading to speciation [29].

Zosterops is represented by various species across large parts of East Africa that inhabit a diverse range of habitats, from the dry lowland savannahs to high mountain cloud forests [30]. Where species have specific environmental niches, they generally do not overlap in their distributions. For example, winter temperatures limit the ranges of two sibling chickadee species in North America creating a dynamic hybrid zone [31]. Similar patterns have been observed in the Heliconius butterfly species-complex in South America [32]. Another example is represented by White-eye bird species. While the Mountain White-eye, Zosterops poliogaster requires moist and cool climatic conditions, its lowland congener, the Abyssinian White-eye Zosterops abyssinicus is found in the dry and warm lowland savannahs, which surround the mountains [30]. These opposite ecological demands cause that both species occur in allopatry. However, in some areas, these taxa occur in parapatry [30, JCH own observations]. In a few areas, the distributions of these species overlap such that they occur in sympatry [30]. However, little is known about their interactions (i.e. hybridization, competition) in such locations. This mosaic-like distribution pattern with allopatric, parapatric, and sympatric situations provides an excellent system to test for potential effects on the species' behaviour and evolutionary processses. We hypothesize that reproductive character displacement will lead to stronger call divergence in sympatric populations compared to allopatric populations; populations with parapatric occurrences are assumed to represent some call similarities in the wake of intermixing along the contact zone. In detail we explore the following questions:

(i) Do the two bird species have distinct contact calls?

(ii) Are the two contrasting distribution patterns (disjunct versus connected) reflected in divergence patterns of contact calls?

(iii) Does parapatry with the congeneric species have an effect on call characteristics?

(iv) Does sympatry with the congener lead to enhanced differences of call characteristics?

\section{Results}

\section{Differentiation between taxa}

Contact calls of the two species were significantly differentiated from each other on the first two $P C$ axes (ANOVA: $\mathrm{PC} 1 \mathrm{DF}=1, \mathrm{~F}=5446.22, \mathrm{p}<0.0001 ; \quad \mathrm{PC} 2$ $\mathrm{DF}=1, \mathrm{~F}=251.08, \mathrm{p}<0.0001)$. The first two principle components explained $93.3 \%$ of the total variance of the data (including both species). The highest and first peaks of calls had the highest loadings for PC1 (0.59 and 0.60 respectively) whereas the starting frequency had the highest loading for PC2 (Table 1) (0.80). Species differentiation was corroborated by Discriminant Function Analysis (Wilks' Lambda $=0.436, \mathrm{~F}=569.52, \mathrm{p}<0.0001$ ); out of the $1808 \mathrm{Z}$. abyssinicus calls, 1615 were identified correctly (89\%); for Z. poliogaster 1128 out of 1286 calls were identified correctly (88\%). Interspecific comparisons of call similarity of populations of both species from parapatric sites showed that their contact calls were more similar to each other than the calls of both species from the allopatric and sympatric populations (ANOVA: $\mathrm{F}=56.07, \mathrm{p}<0.001$ ). 
Table 1 Results from principal component analysis

\begin{tabular}{lccc}
\hline Variable & PC 1 & PC 2 & PC 3 \\
\hline Starting frequency & 0.285 & 0.358 & 0.258 \\
First frequency peak & 0.499 & -0.259 & 0.000 \\
Highest frequency peak & 0.509 & -0.245 & 0.010 \\
End frequency & 0.332 & 0.485 & -0.173 \\
Lowest frequency & 0.350 & 0.538 & -0.038 \\
Total call length & -0.020 & 0.028 & 0.949 \\
Range in frequency & 0.421 & -0.468 & 0.025 \\
Eigenvalue & 3.42 & 1.74 & 1.04 \\
Explained variance & 48.90 & 24.80 & 14.80 \\
\hline
\end{tabular}

Shown are the loadings of the first three principle components explaining $88.5 \%$ of the total variance.

\section{Call patterns within species - differentiation}

In both species two PC axes were identified explaining the major part of the variance $(Z$. abyssinicus $P C 1=$ $38.8 \%, \mathrm{PC} 2=26.7 \% ; Z$. poliogaster $\mathrm{PC} 1=52.4 \%, \mathrm{PC} 2=$ 22.1\%). The lowest frequency and the starting frequency had the highest loadings in $Z$. abyssinicus, whereas the first and highest peaks had the highest loadings in $Z$. poliogaster (Figure 1). ANOVA on the first two PC axes indicated that populations of both species are differentiated from each other ( $Z$. abyssinicus $\mathrm{DF}=11, \mathrm{~F}=23.70$, $\mathrm{p}<0.0001 ; Z$. poliogaster $\mathrm{DF}=8, \mathrm{~F}=596.23, \mathrm{p}<0.0001$ ). Tukey tests showed that the population differentiation in $Z$. abyssinicus was strongly driven by the allopatric population at Hunters' Lodge (PC1, most comparisons $\mathrm{p}<0.0001$, except for the allopatric population close to

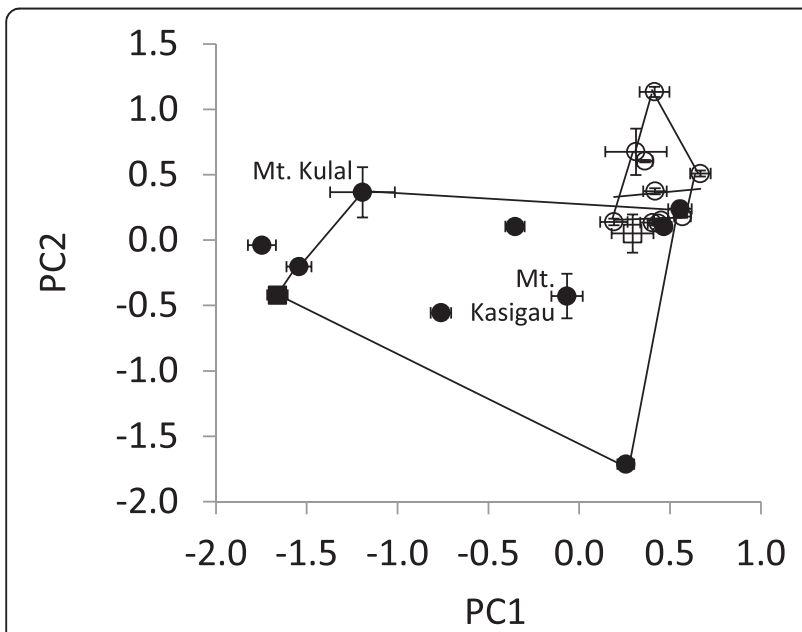

Figure 1 Average positions (error bars denote two standard errors) of $Z$. abyssinicus (parapatric and allopatric - open circles, sympatric - open square) and $Z$. poliogaster populations (parapatric and allopatric - black circles, sympatric - black square) within two dimensional acoustic PCA space (strongly driven by a variation of starting and lowest frequencies and of frequency range in the highland species $Z$. poliogaster, for summary of loadings see Table 1), convex hulls for both species exclude the respective sympatric populations.
Mutito, $\mathrm{p}=0.127)$. In $Z$. poliogaster, all populations were significantly differentiated for PC1 and PC2 (Figure 1). The highest intrapopulation variability was observed in the parapatric populations of Mt. Kasigau and Mt. Kulal.

For both species we found marked longitudinal (Figure 2A) and latitudinal (Figure 2B) trends in contact call patterns, while there was no clear distance decay in call pattern with geographic distance for either species $(Z$. abyssinicus Mantel $\mathrm{r}=-0.08, \mathrm{P}>0.5 ; Z$. poliogaster Mantel $\mathrm{r}=0.21, \mathrm{P}>0.1$ ) or for the whole dataset (Figure 2C,D, Mantel $r=0.12, \mathrm{P}>0.1$ ).

\section{Call patterns within species - acoustic space}

The lowland and highland species significantly differed in acoustic space, i.e. in the variance of contact calls among individuals and among distinct populations (Figure 3). While parapatric and allopatric populations of $Z$ abyssinicus did not differ in contact calls, we found significant differences in Z. poliogaster (Figure 3). The eigenvector ellipse space of the highland $Z$. poliogaster is significantly larger (F-test: $\mathrm{p}<0.001$ ) than that of the lowland $Z$. abyssinicus, indicating the higher contact call variability among highland populations of $Z$. poliogaster. This difference is linked to greater variability of the starting and the lowest frequencies and the frequency range in the highland $Z$. poliogaster (Figure 3).

\section{Differentiation in sympatry}

Nairobi is one location where both species can be found sympatrically. The acoustic spaces of the sympatric Nairobi populations of both species were outside the respective range of the conspecific populations as indicated by the convex hulls in Figure 1 and the eigenvector ellipse areas in Figure 3. Highest frequency and frequency range of the sympatric $Z$. poliogaster population of Nairobi differed significantly $(\mathrm{t}$-test $\mathrm{p}<0.01)$ from all other populations (Figure 1). Frequency range and total call length differentiated the sympatric Nairobi population of $Z$. abyssinicus from the other conspecific populations (t-test $\mathrm{p}<0.001$, Figure $1 \mathrm{C}$ ). Both results show a shift of the sympatric Nairobi populations away from the typical call pattern of either species.

\section{Discussion and conclusion}

Acoustic signal evolution is influenced by features of the physical habitat, community composition, ambient noise, phylogenetic history, morphological and physical constraints inherent to the species [13]. Our data suggest that several of these factors may be involved in the evolution of acoustic signalling in Zosterops. The two Zosterops species we studied have clearly distinct contact calls, mainly differing in the frequency range and the starting frequency of calls. Further, most populations within the two species are differentiated from each other 

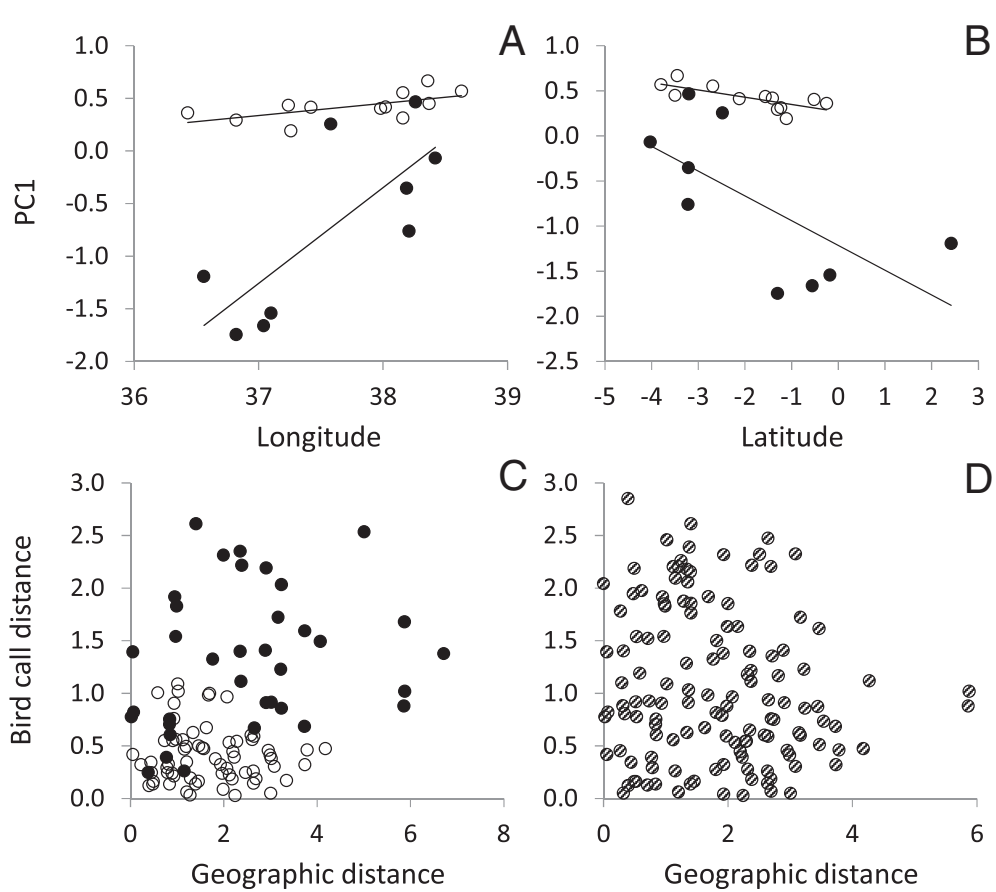

Figure 2 Contact call variation along A) longitudinal and B) latitudinal gradients. Black is the highland Z. poliogaster, white is the lowland Z. abyssinicus. C) Comparison of call distance (calculated as Euclidean distances from the first two principal coordinates axes for all pairs of sites) in response to geographic distance (degrees) for both species, D) respective interspecies comparisons. Regressions in $\mathbf{A}: Z$. poliogaster: $r^{2}=0.59$, $p=0.02 ;$ Z abyssinicus: $r^{2}=0.38, p=0.03$. Regressions in B: Z. poliogaster: $r^{2}=0.44, p=0.05 ; Z$. abyssinicus: $r^{2}=0.56, p=0.006$.

in features of their contact calls. Differentiation was stronger in the isolated mountain populations of Z. poliogaster than in the panmictic lowland Z. abyssinicus. Call patterns in both species show a geographic cline suggesting similar effects of environmental selection. When considering the absence or presence of the congener, parapatric populations have relatively similar contact calls. In contrast, the sympatric populations of $Z$. poliogaster in the highland of Nairobi shows the strongest differentiation in contact calls from the lowland $Z$. abyssinicus suggesting reproductive character displacement. The sympatric $Z$. abyssinicus population also differed from all conspecific populations and shows a

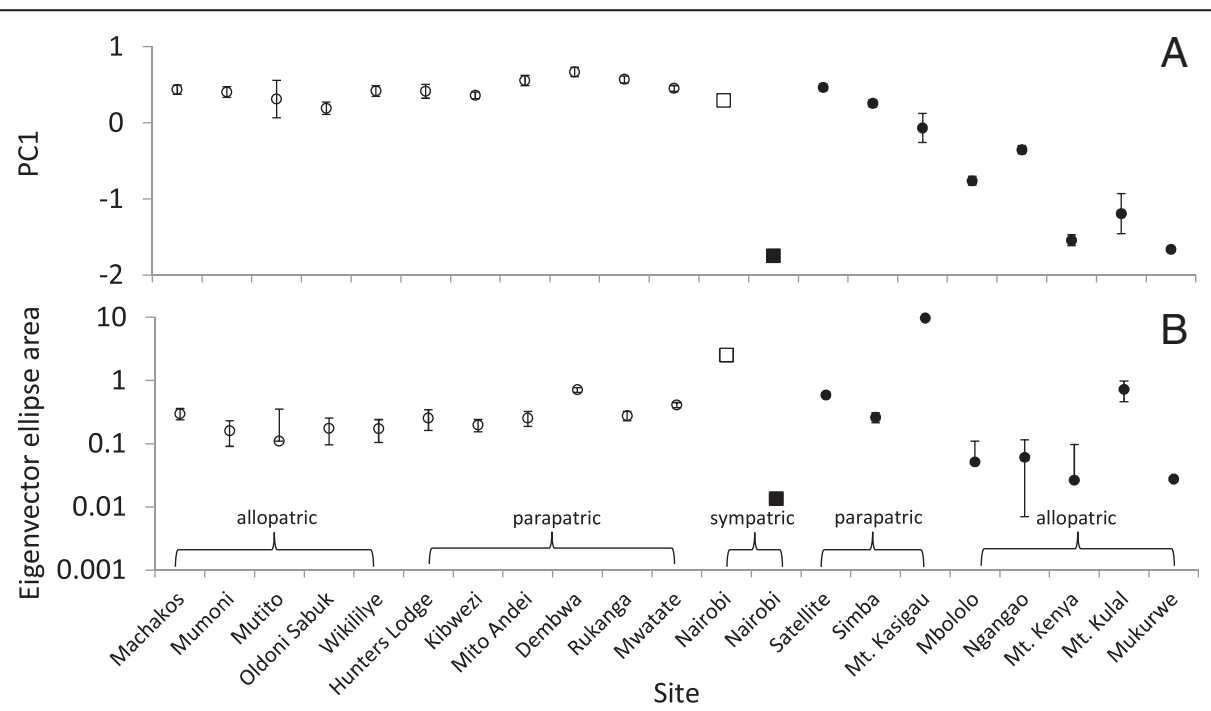

Figure 3 Comparison of acoustic space as measured by first (dominant) eigenvector A. (upper panel) and the ellipse area B. (lower panel) spanned by the first two eigenvectors of principal coordinates analysis occupied by sym-, para-, and allopatric populations of the lowland Zosterops abyssinicus (white) and the highland Z. poliogaster (black). The sympatric Nairobi populations are indicated by squares. 
distinct shift away from $Z$. poliogaster with respect to total call length (Figure 1). In conclusion, it appears that both differences in local environmental conditions as well as selection due to co-existence with congenerics play an important role in the evolution of acoustic signalling in the genus. In the following we discuss these findings in detail.

\section{Species divergence}

The two investigated species of Zosterops are clearly differentiated in their contact calls (Figure 1). Contact calls are considered an important, species-specific, social trait, as shown in previous studies for the genus Zosterops, suggesting a function for the maintenance of flock structure as well as for mate recognition [33,34]. Interestingly, the call patterns of some populations of $Z$. poliogaster strongly overlapped with $Z$. abyssinicus, but never in sympatry, indicating that divergent selection may be relaxed in non-overlapping populations.

\section{Population divergence}

In addition to species differentiation, local populations of both species significantly differed in their calls, but the degree to which populations have diverged was different between the two species. In the lowland Z. abyssinicus, most populations showed little or no divergence in acoustic parameters (except for the population from Hunters Lodge, which was represented by a limited number of recordings, $\mathrm{N}=78$ ). In contras, local populations of the highland $Z$. poliogaster were much stronger differentiated (Figure 1). These different intraspecific patterns could be explained by the contrasting distributions of the two species: Zosterops abyssinicus is widely distributed in the lowland savannahs of East Africa with strong gene flow between local populations and very limited genetic differentiation [35] whereas Z. poliogaster populations are geographically isolated with little gene flow leading to strong genetic and morphologic differentiation [35,36]. The strong acoustic differentiation is also in line with the findings of Baker [37], who studied the bioacoustics in two isolated Zosterops populations and concluded that song patterns can evolve rapidly in this genus even across limited geographical space. However, whether the observed strong differentiation is the result of slight differences in local selective regimes or simply the product of drift cannot be inferred at this point.

In both species acoustic divergence follows geographic clines (Figure 2A,B), but not geographical distance between sites (Figure 2C,D). A correlation of longitude or latitude and acoustic parameters is a common finding in a variety of organisms (e.g. katydids, frogs and birds, [38-41]). In katydids such clinal variation in song patterns has been interpreted to be the result of hybridization and selection along the geographical gradient [41]. While we found clinal variation in both species, the differences among local populations in relation to longitude and latitude are more pronounced in the mountain species. This is likely due to lower connectivity and therefore less individual exchange among mountain populations as compared with the interconnected populations of the lowland taxon. Interestingly the clinal change is directed similarly in both species suggesting that similar environmental forces might be responsible. Several studies have focused on the traits influencing the rates of the evolution of syllable frequencies in different latitudes, altitudes and environments [42,43]. Analyses show that song frequency differences have evolved more rapidly at high latitudes, which may indicate an increased intensity of sexual selection $[42,43]$.

\section{Differentiation in geographic proximity and sympatry}

Besides the geographically isolated (allopatric) populations of both species, we recorded and analysed contact calls from three locations where the two species occur in parapatry (Mt. Kasigau, Taita Hills and Chyulu Hills). Our analyses indicate that calls of both species (highland and lowland taxa) are less different from each other than the average divergence found between both species. The call similarity in these parapatric populations might be the result of several processes: 1) if contact calls are a cultural trait and the species specific call patterns are learned rather than inherited, close proximity to a congener (but not complete overlap) might lead to the accidental admixture of acoustic signals among taxa during the imprinting phase, which has been shown for brood parasites [44]. Mixed singing due to heterospecific copying rather than introgression has also been shown in flycatchers [20]. 2) Alternatively, intermediate call patterns can be the result of occasional hybridization of two closely related species, if calls are genetically determined [45]. 3) A more recent study has suggested that interactions may occur more frequently between evolutionarily 'old' species; in such cases species interactions can drive phenotypic convergence across entire radiations [46]. In our case it is unknown whether contact calls are genetically fixed or learned. Furthermore, the evolutionary age of the species cannot be determined with certainty, therefore, it is difficult to distinguish between these alternatives. Phylogenetic analyses on the group are currently being undertaken and will allow testing of the latter hypothesis.

Our analyses suggest that when both species occur in sympatry (Nairobi population), the calls of each species show different deviations from the average call parameters. While for $Z$. abyssinicus, coexistence has relatively little effect on its contact call, $Z$. poliogaster exhibits a strong shift in call characteristics when compared to allo- and parapatric populations. The song pattern of the sympatric population does not overlap with the congener, and, represents the acoustically most distinct 
(conspecific) population. In addition, the acoustic space of the sympatric population is smaller when compared to all other $Z$. poliogaster highland populations or any population of $Z$. abyssinicus. The picture changes when populations are found in sympatry. Generally, sympatric species are rare in the genus Zosterops, which has led to the suggestion that species diversity is limited by competition with congeners [22]. In systems with multiple closely related species, interspecific competition for signal space [47] and selection against incorrect mate choice and hybridization $[17,18]$ can lead to reproductive character displacement. Hence, if contact calls play a role in reproductive isolation in the system, it is expected that these species will have distinct calls when they occur sympatrically. This suggests that the coexistence with the congener leads to reproductive character displacement.

Character displacement is a common mechanism to reduce the risk of hybridization when closely related species occur in sympatry with examples from crickets [41], frogs [18,17] and birds [20,21]. Reproductive character displacement can either be symmetrical (meaning that both species diverge from their patterns exhibited in allopatry) or it can be asymmetrical (where only one species displaces) [21]. A study of sympatric populations of tinkerbirds for example showed a displacement of song patterns in both sympatric species [21]. In contrast, reproductive character displacement in sympatric populations of chorus frog species was asymmetrical [18]. In this example the rarer species displaced their calls, whereas the more common species at the location remained stable [18]. In our study, only $Z$. poliogaster, which likely has the smaller effective population size, showed character displacement, congruent with the previously described pattern of asymmetrical character displacement [18]. Our observation of reproductive character displacement suggests that contact calls might be under sexual selection in the genus Zosterops and could represent a prezygotic isolation barrier $[48,14]$. In addition, natural selection might further act to prevent hybridization because hybrids might be at a disadvantage as both species have different habitat preferences $[31,32,49]$. Therefore, there might also be ecological selection against hybrids.

Our study indicates distinct calls for the two White-eye species, with different intraspecific variances among local populations. These differences in their call variability reflect their contrasting spatial distribution, with strong disjunction in the highland $Z$. poliogaster populations and large and interconnected populations in $Z$. abyssinicus. Contact calls of heterospecific populations in parapatry are more similar to each other if compared with both, allopatric and sympatric populations. In contrast, when the species occur in sympatry, reproductive character displacement appears to occur leading to strongly divergent call patterns compared to divergence in calls of allopatric or parapatric populations.

\section{Methods}

\section{Study species}

Members of the family Zosteropidae are common models in evolutionary biology as they are known for their rapid diversification rates [22,23,50]. Little is known, however, about the mechanisms leading to such fast speciation. In this study we focus on different populations of the two East African Zosterops species, the highland Z. poliogaster and the lowland $Z$. abyssinicus. The Mountain White-eye, Zosterops poliogaster is restricted to moist and cool climatic conditions and thus occurs exclusively at higher elevations [51]. These specific environmental demands have led to long-term geographic isolation in distinct mountain massifs. In consequence, strong genetic and phenotypic differentiation is present, and has led to a debate on the current taxonomy of this group [30,35,52]. In contrast to these highly disjunct and differentiated populations of the Mountain White-eye, the lowland species $Z$. abyssinicus, the Abyssinian White-eye, is found in dry and warm lowland savannahs in large, interconnected populations [30]. Recent studies on this species showed a lack of intraspecific differentiation, and thus suggest strong panmixia among local populations [35]. It is not known how the high- and lowland species interact at contact zones.

\section{Studied populations}

We recorded contact calls of both the highland species $Z$. poliogaster and the lowland species Z. abyssinicus in areas where species occur (i) in allopatry, (ii) in parapatry (Mt. Kasigau, Taita Hills (two locations in the highland and two locations in the lowland), and Chyulu Hills (two locations in the highland and two locations in the lowland)), and (iii) in sympatry (the highlands of Nairobi). Calls were recorded at the following locations (from south to north): Z. poliogaster from Mt. Kasigau, Taita Hills (including two areas Ngangao, Mbololo, separated by a valley); Chyulu Hills (including the southernmost edge - Simba Valley, and the northernmost edge - Satellite), Nairobi, Mukurwe-ini, Mt. Kenya and Mt. Kulal; Z. abyssinicus was recorded from Rukanga (foothills of Mt. Kaisgau), Mwatate and Dembwa (both at the foothills of Taita Hills), Mtito Andei and Kibwezi (both in close geographic proximity to Chyulu Hills), Hunters Lodge, Machakos, Wikililye, Mutito, Odonio Sabuk, Mumoni Hills and Nairobi. Locations are displayed in Figure 4. An overview of all locations at which contact calls were recorded is provided in Table 2.

\section{Bioacoustic analyses}

Contact calls were recorded during spring and summer 2010 and 2013 using a Sennheiser ME67 directional 


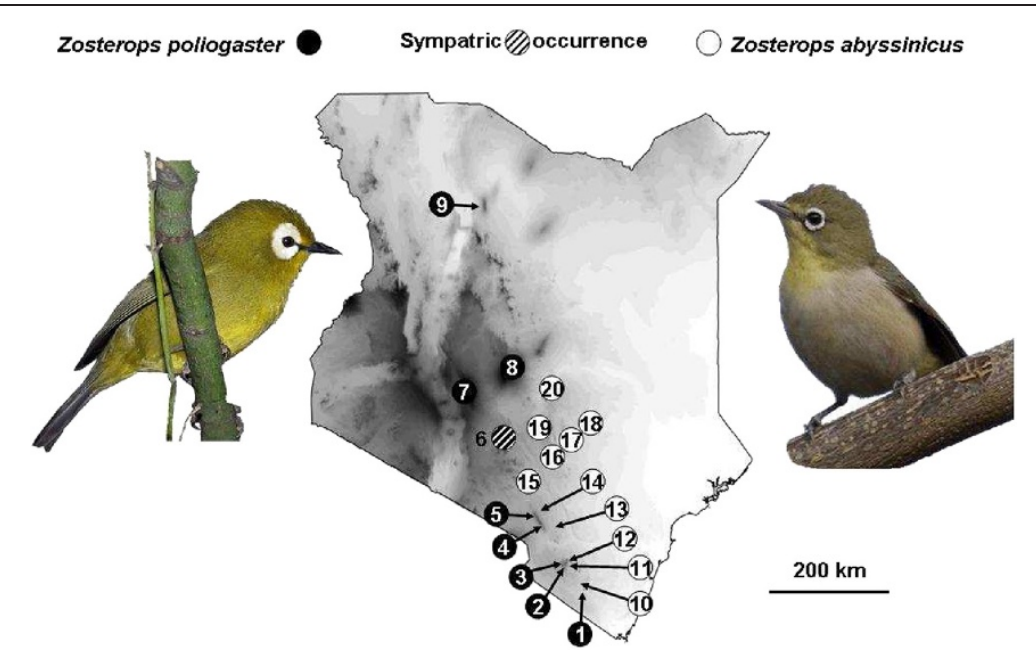

Figure 4 Overview of all locations at which contact calls of the highland Zosterops poliogaster and the lowland Z. abyssinicus were recorded. Site numbers coincide with Table 2.

microphone (Sennheiser, Hanover, Germany). We selected the frequency curve 3 at the Sennheiser microphone to filter lower frequencies during recording. A digital Zoom-H4 recorder was used to save the calls as stereo wav-files. The input level was operated manually and adjusted to $100 \%$. Contact calls of the birds were recorded with a distance of approximately five meters between the microphone and the target bird. The birds use contact calls to persist as flocks when they are moving through the thicket [34, JCH, pers. observation] and these calls may also function in mate recognition [33]. Calls are mostly emitted in series and regular intervals, often in parallel from various individuals. As both species occur in flocks (sizes ranging from a few individuals to some dozens), our data set may contain repeated recordings from same individuals. To limit repeated recording of the same individual (which would lead to non-independence of recordings), recording was stopped after a maximum of 5 clear and loud calls, and the next recording was performed at another edge of the bird flock. Thus we discriminate between the total number of sonograms analysed, and the estimated number of recorded individuals (see Table 2). Calls were recorded between 6:00 am and 6:00 pm for a period of three days per site.

Contact calls of high quality were further processed in the programme AUDACITY vers. 2.01 (Audacity Development Team). Calls affected by strong background noise or overlap with other calls were excluded from further analyses. After deleting calls of bad quality, a total number of 3353 calls remained (on average 160 calls per site \pm 92 , ranging from 17-359 calls per site). For each call we measured the following characters: starting frequency (sometimes congruent with lowest frequency), first peak (mostly congruent with
Table 2 Overview of all populations of the highland Zosterops poliogaster and the lowland Z. abyssinicus used for bioacoustic analyses; given are running numbers (congruent with Figure 4), name of each locality, number of contact calls analysed, date of recording and the coexistence type of each population

\begin{tabular}{llllll}
\hline No & Locality & $\boldsymbol{N}^{*}$ & $\boldsymbol{N}$ & Date & Type \\
\hline Zosterops poliogaster & & & & \\
1 & Mt. Kasigau & $>50$ & 73 & $02-2012$ & parapatric \\
2 & Taita Hills-Ngangao & $>50$ & 190 & $02-2012$ & parapatric \\
3 & Taita Hills-Mbololo & $>50$ & 172 & $02-2013$ & parapatric \\
4 & Chyulu Hills - Simba valley & $>100$ & 248 & $02-2013$ & parapatric \\
5 & Chyulu Hills - Satellite & $>100$ & 301 & $02-2012$ & parapatric \\
6 & Nairobi & $>50$ & 205 & $02-2013$ & sympatric \\
7 & Mukurwe-ini & $>50$ & 174 & $08-2013$ & allopatric \\
8 & Mt. Kenya & $>50$ & 114 & $08-2013$ & allopatric \\
9 & Mt. Kulal & $>10$ & 17 & $02-2010$ & allopatric \\
Zosterops abyssinicus & & & & \\
10 & Rukanga & $>100$ & 259 & $08-2013$ & parapatric \\
11 & Mwatate & $>150$ & 359 & $02-2013$ & parapatric \\
12 & Dembwa & $>100$ & 166 & $02-2013$ & parapatric \\
13 & Mtito Andei & $>50$ & 129 & $02-2013$ & parapatric \\
14 & Kibwezi & $>100$ & 301 & $02-2012$ & parapatric \\
15 & Hunters Lodge & $>50$ & 78 & $02-2012$ & allopatric \\
16 & Machakos & $>50$ & 160 & $08-2013$ & allopatric \\
17 & Wikililye & $>50$ & 133 & $08-2013$ & allopatric \\
18 & Mutito & $>10$ & 19 & $08-2013$ & allopatric \\
19 & Oldonio Sabuk & Mumoni Hills & 93 & $08-2013$ & allopatric \\
6 & Nairobi & 121 & $02-2013$ & allopatric \\
\hline
\end{tabular}

${ }^{*} \mathrm{~N}$ based on estimates, taking into account possible multiple recordings of the same individual. 

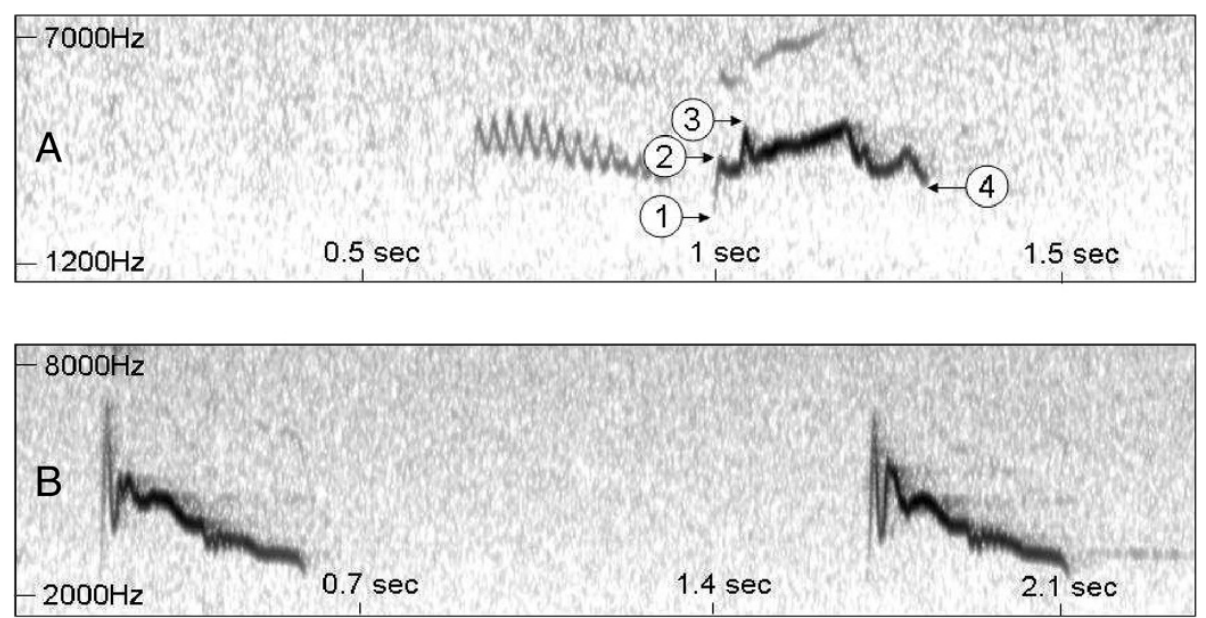

Figure 5 Typical sonograms of the calls of the highland Zosterops poliogaster (A) and lowland Zosterops abyssinicus (B), displaying the parameters analysed for this study: 1: starting frequency (typically congruent with lowest frequency); 2 : first peak (typically congruent with highest frequency); 3: highest frequency; 4: end-frequency (sometimes congruent with lowest frequency); additional characters measured were total call duration (seconds) and frequency range (highest to lowest frequency).

highest frequency), end frequency (mostly congruent with lowest frequency), total duration of call (in seconds) and the range of frequency (difference between the lowest and the highest frequencies). Typical sonograms of both species displaying all analyzed characters are displayed in Figure 5. Spectral analyses were performed blind to site (i.e. population) and species using the programme PRAAT vers. 5.2.15 [53]. The Spectrogram settings menu was used to adjust the range of frequency $(\mathrm{Hz})$ and the dynamic range $(\mathrm{dB})$ depending on background noise.

\section{Statistics on species and population differentiation}

We performed a Principal Component analysis (variance co-variance matrix with Z-transformed data: $\mathrm{Z}=(\mathrm{x}-\mu) / \sigma)$ to reduce data complexity. The first two PC axes explain $74 \%$ of the total variance of the data. Analysis of variance (ANOVA) was performed to test for species and population differences. First, we compared the two species. To further test if species had distinct calls we performed a discriminant function analysis. Two additional ANOVAs were performed to test for population differentiation within each species. Pairwise comparisons of conspecific populations were performed using Tukey's HSD test.

\section{Statistics to test differentiation in sympatry}

We calculated Euclidean distances between contact calls of all pairs of sites using the first two principal component axes (variance - covariance matrix) of the seven characters measured. We then compared these pairwise distances with the respective geographical distances to test if geographically proximate populations of the species differ more strongly in acoustic parameters than distant populations using Mantel correlation. To test for acoustic character displacement in sympatric populations we compared the average acoustic distances between both species (excluding the sympatric populations) with those at the sympatric Nairobi site.

We further estimated the acoustic space that allopatric and sympatric populations of each species occupy. For this all data were Z-transformed to meet assumptions of normality and homogeneity. We estimated the total acoustic space of all populations by generating two-dimensional convex hulls. Convex hulls of $Z$. abyssinicus and $Z$. poliogaster were calculated with the focal population included and excluded. We modified the approach of Jackson et al. [54] and calculated the eigenvector ellipse space spanned by the first two eigenvectors of principal coordinate analysis (Euclidean distances). This method captures a central tendency of acoustic space and is less biased by outliers than the convex hull method [44]. All statistical analyses were performed with Jmp vers. 10.0.0 (SAS Institute Inc.) and Past vers. 3.0 [55]. Our sample sizes are all well above (Table 2) the lower limit for unbiased results of ten data points identified by Jackson et al. [54].

Competing interests

The authors declare that they have no competing interests.

\section{Authors' contributions}

$\mathrm{JCH}$ recorded contact calls and analysed the sonograms, $\mathrm{MH}$ and $\mathrm{WU}$ performed statistical analyses, $\mathrm{MH}$ wrote the first draft of the manuscript, all authors contributed in the interpretation of data and writing of the manuscript. All authors read and approved the final manuscript. 


\section{Acknowledgements}

We thank the German Academic Exchange Service for granting this project to $\mathrm{MH}$ and $\mathrm{JCH}$. We are grateful to Ronald K Mulwa and Kioko Mukua (National Museums of Kenya, Nairobi) for help in the field. We are grateful to the Alexander Koenig Museum Bonn, Germany, and the Medientechnikzentrum of Trier University, Germany for providing technical equipment. Thanks to Scott Bowers for providing the picture of Zosterops abyssinicus. We finally thank two anonymous referees, Dino McMahon and the editor Prof. While for critical comments on a previous versions. This work was supported by the German Research Foundation (DFG) and the Technische Universität München within the funding programme Open Access Publishing.

\section{Author details}

'Terrestrial Ecology Research Group, Department of Ecology and Ecosystem Management, Technische Universität München, Hans-Carl-von-Carlowitz-Platz 2, D-85354 Freising-Weihenstephan, Germany. ${ }^{2}$ Institute of Biology/Zoology, Department of General Zoology, University of Halle, D-06120 Halle, Germany. ${ }^{3}$ Nicolaus Copernicus University in Toruń, Chair of Ecology and Biogeography, PI-87-100 Toruń, Poland.

\section{Received: 15 November 2013 Accepted: 14 May 2014} Published: 2 June 2014

\section{References}

1. Mallet J: Hybridization, ecological races and the nature of species: empirical evidence for the ease of speciation. Phil Trans Roy Soc 2008, 383:2971-2986.

2. Via S: Reproductive isolation between sympatric races of pea aphids. I. Gene flow restriction and habitat choice. Evol 1999, 53:1446-1457.

3. Coyne JA, Orr HA: Sinnauer Associates Sunderland. MA, USA: Sinnauer Associates Sunderland; 2004.

4. Nosil P, Vines TH, Funk DJ: Perspective: reproductive isolation caused by natural selection against immigrants from divergent habitats. Evolution 2005, 59:705-719.

5. Coyne JA, Orr HA: Patterns of speciation in Drosophila. Evolution 1989, 43:362-381.

6. Coyne JA, Orr HA: Patterns of speciation in Drosophila revisited. Evolution 1997, 51:295-303.

7. Kirkpatrick M, Ravingne V: Speciation by natural and sexual selection: models and experiments. The Am Nat 2002, 159:22-35.

8. Bernasconi G, Ashman T-L, Birkhead TR, Bishop JDD, Grossniklaus U, Kubli E, Marshall DL, Schmid B, Skogsmyr I, Snook RR, Taylor D, Till-Bottraud I, Ward PI, Zeh DW, Hellriegel B: Evolutionary ecology of the prezygotic stage. Science 2004, 303:971-975.

9. Rundle HD, Nagel L, Boughman JW, Schluter D: Natural selection and parallel speciation in sympatric sticklebacks. Science 2000, 287:306-308.

10. Schluter D: Ecology and the origin of species. Trends Ecol Evol 2001, 16:372-380.

11. Gerhardt HC: Reproductive character displacement of female mate choice in the grey treefrog, Hyla chrysoscelis. Anim Behav 1994, 47:959-969.

12. Goldberg EE, Lande R: Ecological and reproductive character displacement on an environmental gradient. Evolution 2006, 60:1344-1357.

13. Wilkins MR, Seddon N, Safran RJ: Evolutionary divergence in acoustic signals: causes and consequences. Trend Ecol Evol 2013, 28:156-166.

14. Marshall DC, Cooley JR: Reproductive character displacement and speciation in periodical cicadas, with a description of a new species, 13-year Magicicada neotredecim. Evolution 2000, 54:1313-1325.

15. Tregenza T, Prichard VL, Butlin RK: The originas of premating reproductive isolation: testing hypotheses in the grasshopper Chorthippus parallelus. Evolution 2000, 54:1687-1698.

16. Panhuis TM, Butlin R, Zuk M, Tregenza T: Sexual selection and speciation. Trends Ecol Evol 2001, 16:364-371.

17. Höbel G, Gerhardt HC: Reproductive character displacement in the acoustic communication system of green tree frogs (Hyla cinerea). Evolution 2003, 57:894-904.

18. Lemmon EM: Diversification of conspecific signals in sympatry: geographic overlap drives multidimensional reproductive character displacement in frogs. Evolution 2009, 63:1155-1170.
19. Wallin $L$ : Divergent character displacement in the song of two allospecies: the Pied Flycatcher Ficedula hypoleuca, and the Collared Flycatcher Ficedula albicollis. Ibis 1986, 128:251-259.

20. Haavie J, Borge T, Bures S, Garamszegi LZ, Lampe HM, Moreno J, Qvarnström A, Török J, Sætre G-P: Flycatcher song in allopatry and sympatry - convergence, divergence and reinforcement. J Evol Biol 2004, 17:227-237.

21. Kirschel ANG, Blumstein DT, Smith TB: Character displacement of song and morphology in African Tinkerbirds. Proc Natl Acad Sci U S A 2009, 106:8256-8261.

22. Warren BH, Bermingham E, Prys-Jones R, Thebaud C: Immigration, species radiation and extinction in a highly diverse songbird lineage: White-eyes on Indian Ocean islands. Mol Ecol 2006, 15:3769-3786.

23. Moyle RG, Filardi CE, Smith CE, Diamond J: Explosive Pleistocene diversification and hemispheric expansion of a "great speciator". Proc Natl Acad Sci U S A 2009, 106:1863-1868.

24. Melo $\mathrm{M}$, Warren $\mathrm{BH}$, Jones PJ: Rapid parallel evolution of aberrant traits in the diversification of the Gulf of Guinea white-eyes (Aves, Zosteropidae). Mol Ecol 2011, 20:4953-4967.

25. Oatley G, Voelker G, Crowe TM, Bowie RCK: A multi-locus phylogeny reveals a complex pattern of diversification related to climate and habitat heterogeneity in southern African white-eyes. Mol Phyl Evol 2012, 64:633-644.

26. Diamond JM: Flightlessness and fear of flight in island species. Nature 1981, 293:507-508

27. Bertrand JAM, Bourgeois YXC, Delahaie B, Duval T, Garcia-Jiminez R, Cornuault J, Heeb P, Mila B, Pujol B, Thebaud C: Extremely reduced dispersal and gene flow in an island bird. Heredity 2014, 112:190-196.

28. Clegg SM, Francesca D, Frentiu JK, Tavecchia KG, Owens IPF: 4000 years of phenotypic change in an island bird: heterogeneity of selection over three microevolutionary timescales. Evolution 2008, 62:2393-2410.

29. Gavrilets S: Rapid evolution of reproductive barriers driven by sexual conflict. Nature 2000, 403:886-889.

30. Redman N, Stevenson T, Fanshawe J: Birds of the Horn of Africa: Ethiopia, Eritrea, Dibouti, Somalia, and Socotra, Princeten Field Guide; 2009:488.

31. Gow JL, Peichel CL, Taylor EB: Ecological selection against hybrids in natural populations of sympatric threespine sticklebacks. J Evol Biol 2007, 20:2173-2180.

32. Naisbit RE, Jiggins $C D$, Mallet J: Disruptive sexual selection against hybrids contributes to speciation between Heliconius cydno and Heliconius melpomene. Proc Roy Soc Lond B 2001, 268:1849-1854.

33. Robertson $B C$ : Vocal mate recognition in a monogamous, flock-forming bird, the silvereye Zosterops lateralis. Anim Behav 1996, 1996:303-311.

34. Kondo N, Watanabe S: Contact calls: Information and social function. Jap Psyc Res 2009, 51:197-208.

35. Habel JC, Cox S, Gassert F, Meyer J, Lens L: Population genetics of four East African Mountain White-eye congeners. Conserv Genet 2013, 14:1019-1028.

36. Borghesio L, Ndanganga PK: Threatened birds of Kenya 11: Kulal Whiteeye. Kenya Birds 1999, 7:75-77.

37. Baker MC: Silvereyes (Zosterops lateralis) song differentiation in an islandmainland comparison: analyses of a complex cultural trait. Wilson J Ornithology 2012, 124:454-466.

38. Ryan MJ, Wilczynski W: Evolution ofintraspecific variation in the advertisement call of a cricket frog. Biol J Linn Soc 1991, 44:249-271.

39. Ryan MJ, Rand AS, Weigt LA: Allozyme and advertisement call variation in the Tungara frog, Physalaemus pustulosus. Evolution 1996, 50:2435-2453.

40. Irwin DE: Song variation in an avian ring species. Evolution 2000, 54:998-1010.

41. Cole JA: Clinal variation explainstaxonomic discepancy in the calling songs of shield-back katydids (Orthoptera: Tettigoniidae: Tettigoniinae: Aglaothorax). Biol J Linn Soc 2010, 101:910-921.

42. Weir JT, Wheatcroft D: A latitudinal gradient in rates of evolution of avian syllable diversity and song length. Proc Roy Soc Lond B, 278:1713-1720.

43. Weir JT, Wheatcroft D, Price T: The role of ecological constraint in driving the evolution of avian song frequency across a latitudinal gradient. Evolution 2012, 66:2773-2783.

44. Beltman JB, Haccou P, Cate C: The impact of learning foster species' song on the evolution of specialist avian brood parasitism. Behav Ecol 2003, 14:917-923.

45. Gee JM: No species barrier by call in an avian hybrid zone between California and Gambel's quail (Callipepla californica and C. Gambelii). Biol J Linn Soc 2005, 86:253-264. 
46. Tobias JA, Cornwallis CK, Derryberry EP, Claramunt S, Brumfield RT, Seeon N: Species coexistence and the dynamics of phenotypic evolution in adaptive radiation. Nature 2013, 506:359-363.

47. Chek AA, Bogart JP, Lougheed SC: Mating signal partitioning in multi-species assemblages: a null model test using frogs. Ecol Let 2003, 6:235-247.

48. Fouquette MJ Jr: Speciation in chorus frogs. I. Reproductive character displacement in the Pseudacris nigrita complex. Sys Biol 1975, 24:16-23.

49. Taylor SA, White TA, Hochachka WM, Ferretti V, Curry RL, Lovette I:

Climate-mediated movement of an avian hybrid zone. Current Biol 2014, 24:671-676.

50. Milá B, Warren BH, Heeb P, Thébaud C: The geographic scale of diversification on islands: genetic and morphological divergence at a very small spatial scale in the Mascarene grey white-eye (Aves: Zosterops borbonicus). BMC Evol Biol 2010, 10:158.

51. Mulwa RK, Bennun LA, Ogol CKPO, Lens L: Population status and distribution of Taita White-eye Zosterops silvanus in the fragmented forests of Taita Hills and Mount Kasigau, Kenya. Bird Conserv Int 2007, 17:141-150

52. Borghesio L, Laiolo P: Habitat use and feeding ecology of Kulal White-eye Zosterops kulalensis. Bird Conserv Int 2004, 14:11-24.

53. Boersma PPG: Praat - a system for doing phonetics by computer. Glot International 2002, 5:341-345.

54. Jackson AL, Inger R, Parnell AC, Bearhop S: Comparing isotopic niche width among and within communities: SIBER - Stable Isotope Bayesian Ellipses in R. J Anim Ecol 2011, 80:595-602.

55. Hammer $\varnothing$, Harper DAT, Ryan PD: PAST 3.0: Paleontological Statistics Software Package for Education and Data Analysis. Palaeont Electr 2001, 4:1-9.

doi:10.1186/1471-2148-14-115

Cite this article as: Husemann et al: The evolution of contact calls in isolated and overlapping populations of two white-eye congeners in East Africa (Aves, Zosterops). BMC Evolutionary Biology 2014 14:115.

\section{Submit your next manuscript to BioMed Central and take full advantage of:}

- Convenient online submission

- Thorough peer review

- No space constraints or color figure charges

- Immediate publication on acceptance

- Inclusion in PubMed, CAS, Scopus and Google Scholar

- Research which is freely available for redistribution 